\title{
Review
}

\section{The role of hypoxia-inducible factors in tumorigenesis}

\author{
EB Rankin ${ }^{1}$ and AJ Giaccia*,1
}

Hypoxia-inducible factors (HIFs) are essential mediators of the cellular oxygen-signaling pathway. They are heterodimeric transcription factors consisting of an oxygen-sensitive alpha subunit (HIF- $\alpha$ ) and a constitutive beta subunit (HIF- $\beta$ ) that facilitate both oxygen delivery and adaptation to oxygen deprivation by regulating the expression of genes that control glucose uptake, metabolism, angiogenesis, erythropoiesis, cell proliferation, and apoptosis. In most experimental models, the HIF pathway is a positive regulator of tumor growth as its inhibition often results in tumor suppression. In clinical samples, HIF is found elevated and correlates with poor patient prognosis in a variety of cancers. In summary, HIF regulates multiple aspects of tumorigenesis, including angiogenesis, proliferation, metabolism, metastasis, differentiation, and response to radiation therapy, making it a critical regulator of the malignant phenotype.

Cell Death and Differentiation (2008) 15, 678-685; doi:10.1038/cdd.2008.21; published online 15 February 2008

Tumor hypoxia was first described in the 1950s by radiation oncologists as a frequent cause of failure to radiotherapy in solid tumors. Today, it is evident that tumor hypoxia and the critical molecular mediators of hypoxia, hypoxia-inducible factors (HIFs), regulate multiple steps of tumorigenesis including tumor formation, progression, and response to therapy. This review will focus on our current understanding of HIFs and their role in tumorigenesis.

\section{HIFs}

HIFs facilitate both oxygen delivery and adaptation to oxygen deprivation by regulating the expression of genes that are involved in many cellular processes, including glucose uptake and metabolism, angiogenesis, erythropoiesis, cell proliferation, and apoptosis. ${ }^{1}$ They are members of the PAS (PERARNT (arylhydrocarbon receptor nuclear translocator)-SIM) family of basic helix-loop-helix (bHLH) transcription factors that bind to DNA as heterodimers composed of an oxygensensitive $\alpha$ subunit and a constitutively expressed $\beta$ subunit, also known as ARNT. To date, three HIFs (HIF-1, -2, and -3) have been identified that regulate transcriptional programs in response to low oxygen levels.

HIF-1 was the first HIF family member to be characterized. Using DNA affinity purification, HIF-1 was identified as a hypoxic-induced factor that bound an 18-nt fragment of the EPO enhancer required for the hypoxic activation of EPO in Hep3B cells. $^{2}$ Structural analysis of the HIF-1 $\alpha$ protein revealed that $\mathrm{HIF}-1 \alpha$ contains four distinct domains including a bHLH domain for DNA binding and dimerization, a PAS domain for dimerization and target gene specificity, an oxygen-dependent degradation domain (ODD) required for degradation by the ubiquitin-proteasome pathway, ${ }^{3}$ and two transactivation domains located in the C-terminal portion of the protein (Figure 1). ${ }^{4}$ Notably, HIF-1 has emerged as a critical regulator of the cellular response to hypoxia since it is ubiquitously expressed and induces the expression of many hypoxia-inducible genes. ${ }^{5}$

HIF-2 was the second HIF family member to be identified and shares approximately $48 \%$ amino-acid sequence homology with HIF-1. ${ }^{6-8}$ HIF- $2 \alpha$ is structurally similar to HIF- $1 \alpha$ and contains bHLH, PAS, and ODD motifs with 85,70 and $70 \%$ amino-acid sequence homology to HIF-1 $\alpha$ (Figure 1). ${ }^{6,9}$ Like HIF- $1 \alpha$, HIF- $2 \alpha$ heterodimerizes with ARNT and can induce gene expression. ${ }^{10}$ In contrast to HIF- $1 \alpha$, HIF- $2 \alpha$ expression is restricted to specific cell types that include endothelial cells, glial cells, type II pneumocytes, cardiomyocytes, fibroblasts of the kidney, interstitial cells of the pancreas and duodenum, and hepatocytes. ${ }^{11}$

The third HIF family member, HIF-3 $\alpha$, encodes a bHLH-PAS domain with 57 and $53 \%$ amino-acid sequence identity to HIF$1 \alpha$ and HIF- $2 \alpha$, respectively, and an ODD domain $61 \%$ similar in sequence to the HIF-1 $\alpha$ ODD domain (Figure 1). ${ }^{12}$ Similar to HIF- $1 \alpha$ and HIF- $2 \alpha$, HIF- $3 \alpha$ can dimerize with ARNT and bind to hypoxia response elements (HREs) in vitro. The role of HIF-3 in the hypoxic regulation of target gene expression in vivo is not well understood. ${ }^{12}$ HIF- $3 \alpha$ has multiple splice variants, of which the inhibitory domain PAS protein (IPAS) is the best characterized. IPAS is a truncated form of HIF-3 $\alpha$ that lacks a transactivation domain and functions as a dominant negative by binding to HIF- $1 \alpha$ and preventing the formation of HIF- $1 \alpha /$ ARNT heterocomplexes. ${ }^{13}$ HIF-3 $\alpha$ mRNA can be detected in a variety of tissues, including the thymus, lung, brain, heart, kidney, liver, eye, and brain. ${ }^{12,13}$

1Department of Radiation Oncology, Stanford University School of Medicine, Stanford, CA, USA

${ }^{*}$ Corresponding author: AJ Giaccia, Department of Radiation Oncology, Stanford University, 269 Campus Drive, 1255 CCSR-South, Stanford, CA 94305, USA.

Tel: + 650723 7366; Fax: + 650723 7382; E-mail: giaccia@stanford.edu

Keywords: hypoxia; cancer; HIF; metastasis

Abbreviations: ARNT, arylhydrocarbon receptor nuclear translocator; bHLH, basic helix-loop-helix; HIFs, hypoxia-inducible factors; IPAS, inhibitory domain PAS protein; ODD, oxygen-dependent degradation domain; PAS, PER-ARNT-SIM family

Received 14.11.07; revised 19.12.07; accepted 20.12.07; Edited by NS Chandel; published online 15.2.08 


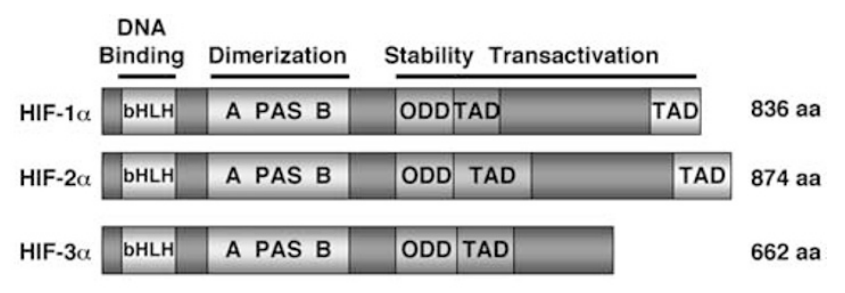

\begin{tabular}{l|l|l|l|}
\hline ARNT & bHLH & A PAS B & TAD \\
\hline
\end{tabular}

\begin{tabular}{|l|l|l|l|}
\hline ARNT-2 & bHLH & A PAS B & TAD \\
\hline
\end{tabular}

Figure 1 Schematic representation of HIF family member protein domains HIFs are members of the basic helix-loop-helix (bHLH)/PER-ARNT-SIM (PAS) domain family of transcription factors that mediate transcriptional responses to oxygen deprivation. They bind to DNA as heterodimers composed of an oxygensensitive HIF- $\alpha$ subunit (HIF- $1 \alpha,-2 \alpha$, or $-3 \alpha$ ) and a constitutive HIF- $\beta$ subunit (ARNT-1 and -2). The bHLH and PAS domains found in all HIF family members mediate DNA binding and dimerization, respectively. HIF- $\alpha$ subunits contain a unique oxygen-dependent degradation domain (ODD) that controls HIF- $\alpha$ stability in an oxygen-dependent manner. In addition, HIF family members contain transactivation domains (TADs) that mediate target gene activation. HIF- $1 \alpha$ and HIF-2 $\alpha$ contain two TADs that contribute to target gene activation

ARNT is the general binding partner for all bHLH/PAS family members. It was first identified as the protein required for dioxin (aryl hydrocarbon) receptor function in hepatocytes. ${ }^{14,15}$ In addition to binding to the aryl hydrocarbon receptor, ARNT can also heterodimerize with the singleminded proteins (SIM1 and SIM2) and the alpha subunits of HIF-1, -2 , and -3 . Similar to the HIF- $\alpha$ subunits, ARNT contains bHLH, PAS, and transactivation domains (Figure 1). ${ }^{14,16}$ However, ARNT lacks an ODD domain, and is therefore constitutively expressed in all tissues under aerobic conditions. ${ }^{17}$

In addition to ARNT, another HIF- $\beta$ subunit, ARNT2, can heterodimerize with HIF- $\alpha$ proteins. Overall, ARNT2, has $57 \%$ amino-acid sequence identity to ARNT. ${ }^{18}$ The $\mathrm{N}$-terminal of the protein containing bHLH and PAS domains shares $81 \%$ similarity with ARNT, suggesting that the two proteins may share similar functions; however, the expression patterns of ARNT and ARNT2 differ (Figure 1). Whereas Arnt mRNA is ubiquitously expressed, Arnt2 expression is restricted to the brain and kidney in adult tissues. ${ }^{18}$ Consistent with Arnt2 expression in the brain, ARNT2 plays a role in mediating hypoxic gene expression in neurons. ${ }^{19}$

\section{Oxygen-Dependent Regulation of HIF}

Under normoxia, HIFs are targeted for proteasomal degradation by the von Hippel-Lindau (VHL) tumor suppressor, pVHL. It has been shown that $\mathrm{pVHL}$ is the substrate recognition component of an E3 ubiquitin ligase complex that interacts with HIF- $\alpha$ in an oxygen-dependent manner. Hydroxylation of conserved proline residues within the HIF- $\alpha$ ODD by prolyl-4hydroxylase domain (PHD)-containing proteins mediates pVHL binding and degradation. ${ }^{20,21}$ Under hypoxia, HIF- $\alpha$ subunits are stabilized and translocate to the nucleus, where they heterodimerize with ARNT and bind to HREs located

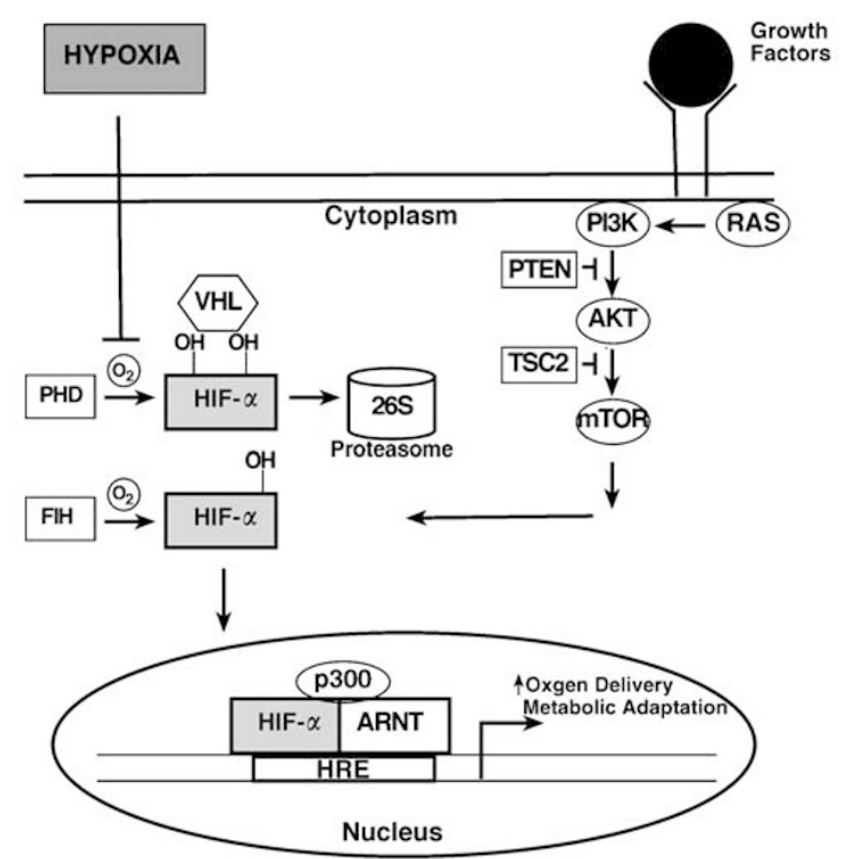

Figure 2 Mechanisms of HIF activation in cancer. Hypoxia is a common mechanism of HIF activation in cancer. Low oxygen tensions inhibit both prolyl-4hydroxylase domain (PHD) and factor inhibiting HIF-1 (FIH-1) activity, which negatively regulates HIF stability and cofactor (p300/CBP) recruitment, respectively. Under normoxic conditions, PHD enzymes (PHD 1-3) utilize oxygen as a substrate to hydroxylate key proline residues located within the HIF- $\alpha$ ODD domain. This hydroxylation event mediates $\mathrm{pVHL}$ binding and subsequent ubiquitination and degradation by the $26 \mathrm{~S}$ proteasome. Under conditions of hypoxia or loss of pVHL, $\mathrm{HIF}-\alpha$ is stabilized and translocates to the nucleus where it heterodimerizes with ARNT and binds to hypoxia response elements (HREs) within regulatory regions of target genes. The HIF heterodimer activates gene expression at these sites upon cofactor (p300/CBP) recruitment. The interaction between HIF and p300 is regulated in an oxygen-dependent manner by $\mathrm{FIH}$. FIH uses oxygen to hydroxylate asparagine residues within the HIF- $\alpha$ C-terminal transactivation domain, thereby preventing p300 binding. HIF activity can also be induced in tumor cells through activation of the PI-3 kinase/Akt-signaling pathway. Growth factor signaling, oncogenic Ras activation, or inhibition of negative regulators, including PTEN and TSC2 can activate the PI-3 kinase/Akt pathway and induce HIF activity in tumor cells

within regulatory elements of HIF target genes. Cell culture studies have shown that HIF stabilization and DNA-binding activity is induced at oxygen concentrations below $6 \%$ oxygen and is maximal at $0.5 \%$ oxygen tensions. ${ }^{22}$ Once stabilized, the HIF- $\alpha /$ ARNT heterodimer activates transcription by recruiting the transcriptional activators p300 and CBP. The interaction between HIF and p300/CBP is also regulated in an oxygen-dependent manner by factor inhibiting HIF-1 (FIH-1), a member of the 2-oxoglutarate and $\mathrm{Fe}$ (II)-dependent oxygenase superfamily. FIH hydroxylates asparagine residues located within the HIF- $\alpha$ C-terminal transactivation domain (CTAD) and prevents p300/CBP binding. ${ }^{23}$ Thus, full activation of HIF transcriptional activity requires both HIF $\alpha$ stabilization and CTAD activation (Figure 2). ${ }^{24}$

Recent studies indicate that mitochondrial reactive oxygen species (ROS) also plays an important role in regulating HIF protein levels under hypoxia. Multiple groups have observed that genetic and chemical inhibition of the mitochondrial electron transport chain and ROS production results in 
decreased HIF stability under hypoxic conditions. ${ }^{25-28}$ The mechanisms by which ROS regulate hypoxic HIF stabilization remain to be defined.

\section{HIF Activation in Cancer}

A recent survey of malignant and normal tissues found that the expression of both HIF- $1 \alpha$ and HIF- $2 \alpha$ are commonly increased in a variety of human tumors, including bladder, breast, colon, glial, hepatocellular, ovarian, pancreatic, prostate, and renal tumors. ${ }^{29}$ In clinical specimens, elevated HIF-1 expression correlates with poor patient outcome in head and neck cancer, nasopharyngeal carcinoma, colorectal, pancreatic, breast, cervical, osteosarcoma, endometrial, ovarian, bladder, glioblastoma, and gastric carcinomas, ${ }^{30-41}$ while elevated HIF-2 expression correlates with poor patient outcome in hepatocellular, colorectal carcinoma, melanoma, ovarian, and non-small cell lung cancers (Table 1). ${ }^{34,39,42,43}$ Collectively, these findings highlight that HIF activation is a common event in cancer and suggest that HIF may play a role in tumorigenesis.

Hypoxia is the best-characterized mechanism of HIF activation in tumors. It has been estimated that $50-60 \%$ of solid tumors contain areas of hypoxic and/or anoxic tissues that develop as a result of an imbalance between oxygen supply and consumption in proliferating tumors. ${ }^{45}$ Low oxygen concentrations may result from increased metabolic activity and oxygen consumption and/or increased tumor cell distance from local capillaries and blood supply. Consistent with tumor hypoxia as a mechanism of HIF activation, HIF protein is commonly detected in perinecrotic regions of sporadic tumors and overlaps with staining for known hypoxic markers. ${ }^{29,46}$

HIF can also be activated in tumors under normoxic conditions through genetic alterations in its oxygen-signaling pathway. As described earlier, VHL plays a central role in regulating HIF transcriptional activity (Figure 2). Inactivation of $\mathrm{VHL}$ results in HIF stabilization and increased target expression irrespective of oxygen concentrations. ${ }^{47,48} \mathrm{VHL}$ mediated regulation of HIF transcriptional activity has important implications for tumor development. Germ-line mutations in $\mathrm{VHL}$ results in $\mathrm{VHL}$ disease, a familial tumor syndrome that predisposes patients to the development of highly vascularized neoplasms, including hemangioblastomas of the retina and central nervous system, renal cell carcinomas (RCCs), endocrine and exocrine pancreatic tumors, as well as pheochromocytomas. ${ }^{49} \mathrm{VHL}$ is also inactivated in the majority of sporadic RCC and hemangioblastomas, highlighting the importance of VHL tumor suppressor activity. ${ }^{50,51}$

Multiple lines of evidence suggest that activation of the PI-3 kinase signaling pathway can also induce HIF activity. Mazure et al. $^{52}$ first observed that inactivation of $\mathrm{PI}-3$ kinase significantly inhibited the hypoxic induction of vascular endothelial growth factor (VEGF) in Ha-ras-transformed cells. Subsequently, it was found that activation of the PI-3 kinase/ Akt pathway through enhanced growth factor signaling or inactivation of negative regulators including PTEN or TSC2 also increased HIF activity (Figure 2).$^{53-56}$ In many cell types, $\mathrm{PI}-3$ kinase/Akt signaling regulates HIF activity in an mTORdependent manner. Although the exact mechanism by which mTOR regulates HIF activity is unclear, evidence suggests that it may have both transcriptional and post-translational effects on HIF. ${ }^{57,58}$

\section{HIF Functions in Cancer}

Tumorigenesis involves a number of alterations in cell physiology that contribute to malignant growth. ${ }^{59}$ Importantly, HIFs have been found to promote key steps in tumorigenesis, including angiogenesis, metabolism, proliferation, metastasis, and differentiation.

Angiogenesis. Neovascularization is critical for tumor progression since the supply of oxygen and nutrients becomes limited in tumor cells that are located more than $100 \mu \mathrm{m}$ away from a blood vessel. ${ }^{60}$ The ability of tumor cells to induce angiogenesis occurs through a multistep process, termed the 'angiogenic switch,' which ultimately tips the balance toward pro-angiogenic factors. ${ }^{59}$ HIF can directly activate the expression of a number of pro-angiogenic

Table 1 HIF activation in human cancer

\begin{tabular}{|c|c|c|c|c|}
\hline Tumor type & HIF-1 & HIF-2 & HIF and poor prognosis & References \\
\hline Bladder & + & + & HIF-1 & Talks et al. 29 \\
\hline Breast & + & + & HIF-1 & Talks et al. ${ }^{29}$ and Schindl et al. ${ }^{35}$ \\
\hline Colorectal & + & + & HIF-1 and HIF-2 & Talks et al. $^{29}$ and Yashimura et al. ${ }^{34}$ \\
\hline Cervical & + & ND & HIF-1 & Birner et al. $^{36}$ \\
\hline Gastric & + & ND & HIF-1 & Mizokami et al. ${ }^{38}$ \\
\hline Glial & + & + & HIF-1 & Talks et al. ${ }^{29}$ and Irie et al. ${ }^{41}$ \\
\hline Head and neck & + & + & HIF-1 and HIF-2 & Winter et al. ${ }^{32}$ \\
\hline Hepatocellular & + & + & HIF-2 & Talks et al. ${ }^{29}$ and Bangoura et al. ${ }^{39}$ \\
\hline Lung NSCLC & + & + & HIF-2 & Giatromanolaki et al. ${ }^{43}$ \\
\hline Melanoma & + & + & HIF-2 & Giatromanolaki et al. ${ }^{42}$ \\
\hline Nasopharyngeal & + & + & $\mathrm{HIF}-1$ & Hui et al. ${ }^{33}$ \\
\hline Osteosarcoma & + & + & HIF-1 & Yang et al. ${ }^{37}$ \\
\hline Ovarian & + & + & HIF-1 and HIF-2 & Talks et al. ${ }^{29}$ and Osada et al. ${ }^{30}$ \\
\hline Pancreatic & + & + & HIF-1 & Talks et al. $^{29}$ and Shibaji et al. ${ }^{31}$ \\
\hline Prostate & + & + & ND & Talks et al. ${ }^{29}$ \\
\hline Renal & + & + & HIF-1 positive & Raval et al. ${ }^{66}$ \\
\hline
\end{tabular}

+, expression was detected; ND, expression levels were not examined; NSCLC, non-small-cell lung cancer Expression levels were determined by immunohistochemical methods 
factors, including VEGF, VEGF receptors FLT-1 and FLK-1, plasminogen activator inhibitor-1 (PAl-1), angiopoietins (ANG-1 and -2), platelet-derived growth factor B (PDGF-B), the TIE-2 receptor, and matrix metalloproteinases MMP-2 and -9 (Figure 3, for a recent review). ${ }^{61}$ Of all the proangiogenic factors induced by HIF, VEGF-A is particularly noteworthy since it has potent angiogenic properties and is expressed in a large number of human tumors. $^{62}$

In both human cell lines and murine model systems, HIF signaling has been shown to be required for the regulation of VEGF and tumor angiogenesis. However, the relative contribution of individual HIF family members in this process is controversial. A proangiogenic role has been reported for HIF-1. Notably, HIF-1-deficient ES cells formed significantly smaller teratocarcinomas that exhibited reduced tumor vessel density and VEGF levels compared to teratocarcinomas derived from wild-type ES cells. ${ }^{63,64}$ VEGF expression and angiogenesis were also found to be HIF-1 dependent in hypoxic astrocytes providing further evidence for HIF-1mediated angiogenesis. ${ }^{44,65}$ Recent studies suggest that HIF-2 can also regulate angiogenesis. Raval et al. ${ }^{66}$ observed that VEGF expression was preferentially induced by HIF-2 in VHL-deficient RCC cells that expressed both HIF-1 and -2. To directly compare the relative contributions of HIF-1 and -2 in tumorigenesis, Covello et al. ${ }^{67}$ generated teratocarcinomas derived from ES cells in which HIF-2 $\alpha$ was knocked into the HIF- $1 \alpha$ locus, thereby expanding HIF-2 expression. Teratomas derived from HIF- $2 \alpha$ knock-in ES cells were larger and exhibited increased vascularity and VEGF expression

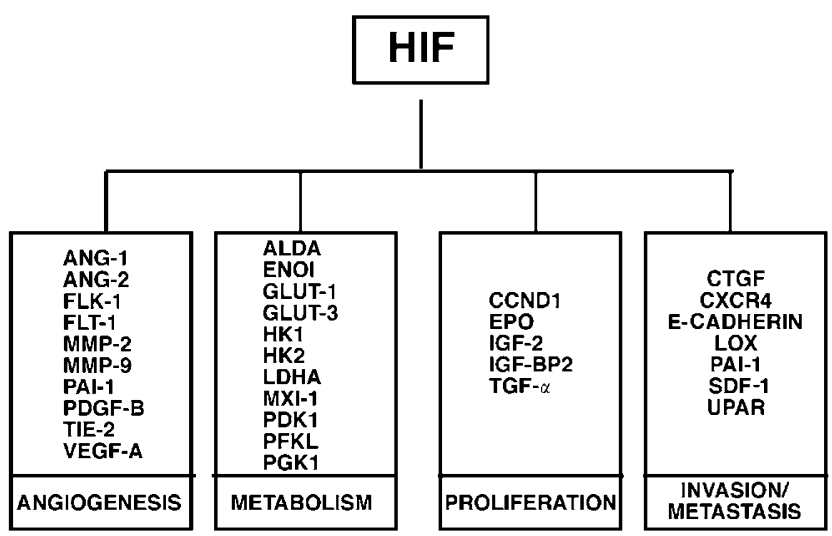

Figure 3 List of HIF-regulated genes that promote key aspects of tumorigenesis. HIF regulates the expression of over 100 genes that regulate key aspects of tumorigenesis, including angiogenesis, metabolism, proliferation, invasion, and metastasis. ALDA, aldolase A; ANG-1, angiopoietin 1; ANG-2, angiopoietin 2; CCND1, cyclin D1; CTGF, connective tissue growth factor; CXCR4, C-X-C chemokine receptor type 4; E-cadherin; EPO, erythropoietin; ENO1, enolase 1; FLT-1, VEGF receptor 1; FLK-1, VEGF receptor 2; GLUT-1, glucose transporter1; GLUT-3, glucose transporter-3; HK1, hexokinase 1; HK2, hekokinase 2; IGF-2, insulin growth factor-2; IGF-BP2, IGF-factor-binding protein 2; LDHA, lactate dehydrogenase A; LOX, lysyl oxidase; MMP-2, matrix metalloproteinase-2; MMP-9, matrix metalloproteinase-9; MXI-1, max interactor 1 ; PAI-1, plasminogen activator inhibitor-1; PDGF-B, platelet-derived growth factor-B; PDK1, pyruvate dehydrogenase kinase 1; PFKL, phosphofructokinase L; PGK1, phosphoglycerate kinase 1; SDF-1, stromal-derived factor 1 ; TGF- $\alpha$, transforming growth factor- $\alpha$; TIE-2; UPAR, urokinase plasminogen activator receptor; VEGF, vascular endothelial growth factor compared to wild-type (HIF-1 $\alpha$ expressing)-derived teratomas, suggesting that HIF-2 plays an important role in promoting tumor angiogenesis and growth. Collectively, these findings demonstrate that both HIF-1 and -2 can activate VEGF and tumor angiogenesis; however, their individual contributions appear to be cell-type dependent. These differences may be attributed to different levels of HIF-1 and -2 in individual cell types and may be affected by cell-specific cofactors that modulate HIF activity.

Metabolism. It was noted over 70 years ago that cancer cells shift glucose metabolism from oxidative to glycolytic pathways. This process known as the Warburg effect, involves decreased mitochondrial respiration and increased lactate production even in the presence of oxygen. ${ }^{68}$ It is well established that HIF, in particular HIF-1, directly regulates the expression of a number of genes involved in glycolytic metabolism, including glucose transporters, glycolytic enzymes, lactate production, and pyruvate metabolism in both hypoxic and normoxic (e.g. VHL deficient) cells (Figure 3). ${ }^{10,69}$ Recent studies using transformed cell lines show that HIF-1 can also regulate cellular metabolism by controlling mitochondrial respiration. Zhang et al. ${ }^{70}$ observed that HIF-1 negatively regulates mitochondrial mass and oxygen consumption in VHL-deficient RCC cells. The mechanism by which HIF mediates these effects appears to be through inhibition of C-Myc activity. HIF-1 was found to negatively regulate $\mathrm{C}-\mathrm{Myc}$ activity and mitochondrial respiration through transcriptional activation of the C-Myc repressor, $\mathrm{MXI}-1$, and through regulation of $\mathrm{C}-\mathrm{Myc}$ protein stability. Collectively, these findings demonstrate that HIF controls multiple aspects of metabolism through direct transcriptional activation of genes involved in glucose metabolism and indirectly by regulating C-Myc activity. These observations indicate that HIF is an important mediator of metabolism in cancer.

Proliferation. HIF-2 plays an important role in promoting tumor growth. In VHL-deficient RCC cells, HIF-2 is both necessary and sufficient to maintain tumor growth. ${ }^{71,72}$ Furthermore, tumors generated from RCC cell lines overexpressing HIF-2 grow at a faster rate compared to HIF-1-overexpressing tumors. ${ }^{66}$ Covello et al. ${ }^{67}$ demonstrated that teratomas derived from ES cells with HIF- $2 \alpha$ in the place of the HIF-1 $\alpha$ locus are larger and exhibit increased proliferation rates compared to wild-type (HIF-1 $\alpha$ expressing) teratomas. While HIF-2 may facilitate tumor growth through multiple mechanisms, recent studies indicate that HIF-2 can positively regulate cell proliferation.

One mechanism by which HIF-2 controls cellular proliferation is through modulation of C-Myc activity. C-Myc promotes cellular proliferation by regulating the expression of genes involved in cell cycle control including cyclins (cyclin D2) and cyclin kinase inhibitors (p21 and p27). ${ }^{73}$ Unlike HIF-1, HIF-2 promotes C-Myc-dependent activation of cyclin D2 and repression of p27 in RCC cells. ${ }^{74}$ How HIF-2 preferentially promotes C-Myc activity remains unclear, but may occur through alterations in C-Myc interactions with transcriptional cofactors, including Sp1, Miz1, and Max. ${ }^{74}$ 
HIF-2 may also drive cell cycle progression through the activation of cyclin D1. ${ }^{66}$ Cyclin D1 is a well-characterized cell cycle regulatory protein that is upregulated in many cancers. Recent studies have shown a correlation between HIF-2mediated cyclin D1 expression and tumor growth in RCC cells. ${ }^{66,75}$ Whether cyclin D1 is a direct HIF target remains to be determined.

Metastasis. Metastasis is a critical step in tumor pathogenesis and is the primary cause of human cancer deaths. It occurs in a series of distinct steps that include tumor cell invasion, intravasation, extravasation, and proliferation. HIF activation correlates with metastasis in multiple tumors and can promote metastasis through the regulation of key factors governing tumor cell metastatic potential, including E-cadherin, lysyl oxidase (LOX), CXCR4, and stromal-derived factor 1 (SDF-1) (Figure 3).

E-cadherin is a key factor governing metastatic potential in the majority of epithelial cancers. It is a cellular adhesion molecule that regulates cell-cell adhesion and stimulates antigrowth signals through cytoplasmic interactions with $\beta$ catenin (for review). ${ }^{59}$ The importance of E-cadherin in regulating metastasis is underscored by the findings that E-cadherin inactivation enhances metastatic potential and forced expression of E-cadherin in cancer cells inhibits metastasis. ${ }^{59}$ HIF has recently been described as a critical factor for the regulation of E-cadherin expression in ovarian carcinoma and VHL-deficient renal cells. ${ }^{76,77}$ It has been proposed that HIF mediates repression of $\mathrm{E}$-cadherin expression through the upregulation of E-cadherin-specific repressors, including Snail and SIP1. ${ }^{78}$

HIF also promotes metastasis through activation of the extracellular matrix protein LOX. ${ }^{79} \mathrm{LOX}$ is an amine oxidase involved in extracellular matrix formation. Increased LOX expression is correlated with decreased distant metastasisfree survival and overall survival in patients with breast and head and neck cancer. In addition, LOX activation promotes the invasive and metastatic potential of breast cancer cells. Erler et al. ${ }^{79}$ recently reported that LOX is a direct HIF target in hypoxic tumor cells and that genetic and pharmacologic inhibition of LOX is sufficient to prevent hypoxia-induced cell invasion and metastasis in vitro and in vivo. These findings indicate that LOX is a critical factor in hypoxia-induced metastasis.

Interactions between the chemokine receptor CXCR4 and its ligand SDF-1 play an important role in the directional migration of metastatic tumor cells. CXCR4 is the most common chemokine expressed in tumors and SDF-1 is highly expressed at sites of metastasis, including the lung, bone marrow, and liver. ${ }^{80}$ Studies have shown that HIF is a potent inducer of both CXCR4 and SDF-1 expression in a variety of cell types, including VHL-deficient RCCs, non-small cell lung cancer, glioblastomas, and endothelial cells. ${ }^{80-84}$

Differentiation. Accumulating evidence suggests that cancer stem cells are important mediators of tumor growth. According to the 'cancer stem cell' hypothesis, tumors are thought to originate from a small population of proliferating cells that maintain the ability to self-renew and differentiate into a heterogeneous population. ${ }^{85}$ It is well documented that hypoxia and HIF promotes an undifferentiated state in a variety of cell types. Hypoxia has been shown to prevent the differentiation of progenitor cells and promote dedifferentiation of cancer cells. ${ }^{86-89}$ Gustafsson et al. $^{86}$ has provided evidence to suggest that Notch plays an important role in maintaining a dedifferentiated state under hypoxia in multiple cell types, including cortical neural stem cells, myogenic satellite cells, and $\mathrm{C} 2 \mathrm{C} 12$ cells. In these cells, hypoxia enhanced Notch signaling in a HIF-dependent manner, whereby HIF- $1 \alpha$ interacts with and stabilizes the Notch ICD domain. In addition to regulating Notch, HIF could also promote an undifferentiated state by directly activating the expression of genes involved in stem cell maintenance. Evidence suggests that primitive hematopoietic and embryonic stem (ES) cells reside in an hypoxic microenvironment, suggesting that low oxygen tensions may play a role in maintaining stem cell fate. ${ }^{90,91}$ In support of this notion, hypoxia has been shown to maintain human ES (hES) cells in an undifferentiated state and maintain stem cell pluripotency. ${ }^{92}$ Interestingly, maintenance of a dedifferentiated state in hypoxic hES cells correlated with the expression of Oct4, transcription factor involved in maintaining an undifferentiated state in ES that has recently been identified as one of four factors sufficient to reprogram fibroblasts to a cell that exhibits ES cell morphology and growth properties. ${ }^{93}$ Covello et al. ${ }^{94}$ recently demonstrated that HIF-2 directly regulates Oct4 expression in 293 and hypoxic human RCC cells. Whether Oct4 and Notch are required to maintain an undifferentiated state in hypoxic tumor cells remains to be determined.

\section{HIF and Tumor Inhibition}

Despite HIF's protumorigenic properties, HIF has also been reported to inhibit tumor growth. Carmeliet et al. ${ }^{64}$ observed that tumors derived from HIF-1-deficient ES cells formed larger tumors compared to wild-type tumors. In addition, HIF activation has been reported to inhibit tumor growth in additional cell types, including glioblastomas and VHLdeficient fibrosarcomas. ${ }^{95,96}$ While all of these tumor models confirmed a positive role for HIF in tumor angiogenesis, tumor growth inhibition was associated with decreased proliferation and increased apoptosis.

Recent studies have elucidated mechanisms by which HIF-1 can negatively regulate tumor growth. First, HIF-1 can indirectly induce cell cycle arrest by inhibiting Myc activity. It has been proposed that a physical interaction between $\mathrm{HIF}-1 \alpha$ and Myc prevents Myc-mediated repression of the cyclin kinase inhibitor p21. ${ }^{97}$ Second, HIF can induce apoptosis through both direct and indirect mechanisms. It has been reported that HIF-1 can directly induce the expression of the proapoptotic genes BNIP3 and NIX in a variety of human cancer cell lines, macrophages, and endothelial cells. ${ }^{98,99}$ The mechanisms of BNIP3-mediated cell death under hypoxia are not well understood. A recent report suggests that BNIP3 is required for hypoxia-induced macroautophagy. ${ }^{100}$ Autophagy is generally thought of as a cellular survival mechanism that involves recycling of amino acids and fatty acids to produce energy under conditions of nutrient deprivation and stress; however, sustained autophagy can result in 
autophagic cell death. Whether macroautophagy is induced by HIF as a mechanism for cellular survival and or cell death remains to be determined. HIF can also indirectly induce apoptosis by promoting glucose deprivation. Biju et al. ${ }^{101}$ observed that in the presence of low glucose, HIF-1 promotes hypoxia-induced cell death in renal epithelial cells as a result of rapid glucose depletion. This finding suggests that HIF-1mediated glycolysis may be a mechanism of hypoxia-induced apoptosis in cell types where glucose stores are limited.

\section{HIF and Radiotherapy}

Radiotherapy is a highly effective treatment for cancer. The targets of radiotherapy are both tumor cells and tumor vasculature. Previous studies have indicated that radiation results in a reoxygenation-dependent increase in HIF-1 activity by two distinct mechanisms. It has been proposed that tumor reoxygenation results in both HIF-1 stabilization and enhanced translation of HIF targets through the release of ROS and stress granule depolymerization, respectively. ${ }^{102}$ The effects of HIF on tumor radiosensitivity are twofold. On one hand, HIF-1 stabilization promotes tumor vasculature radioresistance through the release of proangiogenic cytokines such as VEGF. ${ }^{102}$ In contrast, HIF-1 can also induce tumor radiosensitivity through the induction of apoptosis. ${ }^{103}$ Overall, it appears that HIF-1 stabilization promotes radioresistance since HIF-1-deficient tumors are more sensitive to radiation compared to wild-type tumors. ${ }^{103}$ These findings suggest that combined radiation and antiangiogenic therapy may be an effective strategy for activating HIF-mediated radiosensitivity. In support of this notion, Magnon et al. ${ }^{104}$ observed that a combination of radioiodide and antiangiogenic therapies significantly inhibited tumor growth in xenograft and spontaneous tumor model systems. Notably, tumor growth inhibition was associated with HIF-1-dependent tumor cell apoptosis. These findings support the use of angiogenic inhibitors to overcome HIF-1-dependent radioresistance in tumor therapy.

\section{Conclusion}

In conclusion, HIFs are transcription factors that mediate cellular adaptations to oxygen deprivation. Over 100 direct HIF target genes have been identified that regulate a number of cellular processes, including glucose metabolism, angiogenesis, erythropoiesis, proliferation, and invasion. HIF can also indirectly regulate cellular processes such as proliferation and differentiation through interactions with other signaling proteins such as C-Myc and Notch. There are multiple mechanisms by which HIF can become activated and promote tumor progression. In this review, we have summarized recent findings that implicate HIF in the regulation of key steps in tumorigenesis.

Acknowledgements. We thank Dr. Andrew Rankin for critical reading of the manuscript and apologize to those colleagues whose work was not cited due to space limitations.

1. Semenza GL. HIF-1 and mechanisms of hypoxia sensing. Curr Opin Cell Biol 2001; 13: 167-171.
2. Wang GL, Semenza GL. Purification and characterization of hypoxia-inducible factor 1 . J Biol Chem 1995; 270: 1230-1237.

3. Huang LE, Gu J, Schau M, Bunn HF. Regulation of hypoxia-inducible factor 1alpha is mediated by an $\mathrm{O}_{2}$-dependent degradation domain via the ubiquitin-proteasome pathway. Proc Natl Acad Sci USA 1998; 95: 7987-7992.

4. Pugh CW, O'Rourke JF, Nagao M, Gleadle JM, Ratcliffe PJ. Activation of hypoxiainducible factor-1; definition of regulatory domains within the alpha subunit. J Biol Chem 1997; 272: 11205-11214.

5. Wenger RH, Rolfs A, Marti HH, Guenet JL, Gassmann M. Nucleotide sequence, chromosomal assignment and mRNA expression of mouse hypoxia-inducible factor-1 alpha. Biochem Biophys Res Commun 1996; 223: 54-59.

6. Tian H, McKnight SL, Russell DW. Endothelial PAS domain protein 1 (EPAS1), a transcription factor selectively expressed in endothelial cells. Genes Dev 1997; 11: 72-82.

7. Ema M, Taya S, Yokotani N, Sogawa K, Matsuda Y, Fujii-Kuriyama Y. A novel bHLH-PAS factor with close sequence similarity to hypoxia-inducible factor 1alpha regulates the VEGF expression and is potentially involved in lung and vascular development. Proc Natl Acad Sci USA 1997; 94: 4273-4278.

8. Flamme I, Fröhlich T, von Reutern M, Kappel A, Damert A, Risau W. HRF, a putative basic helix-loop-helix-PAS-domain transcription factor is closely related to hypoxiainducible factor-1 alpha and developmentally expressed in blood vessels. Mech Dev 1997; 63: 51-60.

9. Hu CJ, Sataur A, Wang L, Chen H, Simon MC. The N-terminal transactivation domain confers target gene specificity of hypoxia-inducible factors HIF-1alpha and HIF-2alpha. Mol Biol Cell 2007; 18: 4528-4542.

10. Hu CJ, Wang LY, Chodosh LA, Keith B, Simon MC. Differential roles of hypoxia-inducible factor 1alpha (HIF-1alpha) and HIF-2alpha in hypoxic gene regulation. Mol Cell Biol 2003; 23: 9361-9374.

11. Wiesener MS, Jürgensen JS, Rosenberger $C$, Scholze CK, Hörstrup JH, Warnecke $C$ et al. Widespread hypoxia-inducible expression of HIF-2alpha in distinct cell populations of different organs. FASEB J 2003; 17: 271-273.

12. Gu YZ, Moran SM, Hogenesch JB, Wartman L, Bradfield CA. Molecular characterization and chromosomal localization of a third alpha-class hypoxia inducible factor subunit HIF3alpha. Gene Expr 1998; 7: 205-213.

13. Makino $Y$, Cao R, Svensson K, Bertilsson G, Asman M, Tanaka $H$ et al. Inhibitory PAS domain protein is a negative regulator of hypoxia-inducible gene expression. Nature 2001; 414: 550-554.

14. Reyes $\mathrm{H}$, Reisz-Porszasz $\mathrm{S}$, Hankinson $\mathrm{O}$. Identification of the Ah receptor nuclear translocator protein (Arnt) as a component of the DNA binding form of the Ah receptor. Science 1992; 256: 1193-1195.

15. Hoffman EC, Reyes H, Chu FF, Sander F, Conley LH, Brooks BA et al. Cloning of a factor required for activity of the Ah (dioxin) receptor. Science 1991; 252: 954-958.

16. Whitelaw ML, Gustafsson JA, Poellinger L. Identification of transactivation and repression functions of the dioxin receptor and its basic helix-loop-helix/PAS partner factor Arnt: inducible versus constitutive modes of regulation. Mol Cell Biol 1994; 14: 8343-8355.

17. Huang LE, Arany Z, Livingston DM, Bunn HF. Activation of hypoxia-inducible transcription factor depends primarily upon redox-sensitive stabilization of its alpha subunit. J Biol Chem 1996; 271: 32253-32259.

18. Hirose K, Morita M, Ema M, Mimura J, Hamada H, Fujii $\mathrm{H}$ et al. cDNA cloning and tissuespecific expression of a novel basic helix-loop-helix/PAS factor (Arnt2) with close sequence similarity to the aryl hydrocarbon receptor nuclear translocator (Arnt). Mol Cell Biol 1996; 16: 1706-1713.

19. Maltepe E, Keith B, Arsham AM, Brorson JR, Simon MC. The role of ARNT2 in tumor angiogenesis and the neural response to hypoxia. Biochem Biophys Res Commun 2000; 273: $231-238$.

20. Jaakkola P, Mole DR, Tian YM, Wilson MI, Gielbert J, Gaskell SJ et al. Targeting of HIF-alpha to the von Hippel-Lindau ubiquitylation complex by $\mathrm{O}_{2}$-regulated prolyl hydroxylation. Science 2001; 292: 468-472.

21. Ivan M, Kondo K, Yang H, Kim W, Valiando J, Ohh M et al. HIFalpha targeted for VHLmediated destruction by proline hydroxylation: implications for $\mathrm{O}_{2}$ sensing. Science 2001; 292: 464-468.

22. Jiang BH, Semenza GL, Bauer C, Marti HH. Hypoxia-inducible factor 1 levels vary exponentially over a physiologically relevant range of $\mathrm{O}_{2}$ tension. Am J Physiol 1996; 271 : C1172-C1180.

23. Mahon PC, Hirota K, Semenza GL. FIH-1: a novel protein that interacts with HIF-1alpha and VHL to mediate repression of HIF-1 transcriptional activity. Genes Dev 2001; 15 : 2675-2686.

24. Lando D, Peet DJ, Whelan DA, Gorman JJ, Whitelaw ML. Asparagine hydroxylation of the HIF transactivation domain a hypoxic switch. Science 2002; 295: 858-861.

25. Chandel NS, Maltepe E, Goldwasser E, Mathieu CE, Simon MC, Schumacker PT. Mitochondrial reactive oxygen species trigger hypoxia-induced transcription. Proc Natl Acad Sci USA 1998; 95: 11715-11720.

26. Guzy RD, Hoyos B, Robin E, Chen H, Liu L, Mansfield KD et al. Mitochondrial complex III is required for hypoxia-induced ROS production and cellular oxygen sensing. Cell Metab 2005; 1: 401-408.

27. Mansfield KD, Guzy RD, Pan Y, Young RM, Cash TP, Schumacker PT et al. Mitochondrial dysfunction resulting from loss of cytochrome $c$ impairs cellular oxygen sensing and hypoxic HIF-alpha activation. Cell Metab 2005; 1: 393-399. 
28. Brunelle JK, Bell EL, Quesada NM, Vercauteren K, Tiranti V, Zeviani M et al. Oxygen sensing requires mitochondrial ROS but not oxidative phosphorylation. Cell Metab 2005; 1: 409-414.

29. Talks KL, Turley H, Gatter KC, Maxwell PH, Pugh CW, Ratcliffe PJ et al. The expression and distribution of the hypoxia-inducible factors HIF-1alpha and HIF-2alpha in normal human tissues, cancers, and tumor-associated macrophages. Am J Pathol 2000; 157 411-421.

30. Osada R, Horiuchi A, Kikuchi N, Yoshida J, Hayashi A, Ota M et al. Expression of hypoxia-inducible factor 1alpha, hypoxia-inducible factor 2alpha, and von Hippel-Lindau protein in epithelial ovarian neoplasms and allelic loss of von Hippel-Lindau gene: nuclear expression of hypoxia-inducible factor 1alpha is an independent prognostic factor in ovarian carcinoma. Hum Pathol 2007; 38: 1310-1320.

31. Shibaji T, Nagao M, Ikeda N, Kanehiro H, Hisanaga M, Ko S et al. Prognostic significance of HIF-1 alpha overexpression in human pancreatic cancer. Anticancer Res 2003; 23. $4721-4727$.

32. Winter SC, Shah KA, Han C, Campo L, Turley H, Leek $\mathrm{R}$ et al. The relation between hypoxia-inducible factor (HIF)-1alpha and HIF-2alpha expression with anemia and outcome in surgically treated head and neck cancer. Cancer 2006; 107: 757-766.

33. Hui EP, Chan AT, Pezzella F, Turley H, To KF, Poon TC et al. Coexpression of hypoxiainducible factors 1alpha and 2alpha, carbonic anhydrase IX, and vascular endothelial growth factor in nasopharyngeal carcinoma and relationship to survival. Clin Cancer Res 2002; 8: 2595-2604

34. Yoshimura H, Dhar DK, Kohno H, Kubota H, Fujii T, Ueda S et al. Prognostic impact of hypoxia-inducible factors 1alpha and 2alpha in colorectal cancer patients: correlation with tumor angiogenesis and cyclooxygenase-2 expression. Clin Cancer Res 2004; 10: 8554-8560.

35. Schindl M, Schoppmann SF, Samonigg H, Hausmaninger $\mathrm{H}$, Kwasny W, Gnant $\mathrm{M}$ et al Overexpression of hypoxia-inducible factor 1alpha is associated with an unfavorable prognosis in lymph node-positive breast cancer. Clin Cancer Res 2002; 8: 1831-1837.

36. Birner P, Schind M, Obermair A, Plank C, Breitenecker G, Oberhuber G et al. Overexpression of hypoxia-inducible factor 1alpha is a marker for an unfavorable prognosis in early-stage invasive cervical cancer. Cancer Res 2000; 60: 4693-4696.

37. Yang QC, Zeng BF, Dong Y, Shi ZM, Jiang ZM, Huang J. Overexpression of hypoxiainducible factor-1 $\backslash\{$ alphal\} in human osteosarcoma: correlation with clinicopathological parameters and su. Jpn J Clin Oncol 2007; 37: 127-134.

38. Mizokami K, Kakeji Y, Oda S, Maehara Y. Relationship of hypoxia-inducible factor 1alpha and p21WAF1/CIP1 expression to cell apoptosis and clinical outcome in patients with gastric cancer. World J Surg Oncol 2006; 4: 94.

39. Bangoura G, Liu ZS, Qian Q, Jiang CQ, Yang GF, Jing S. Prognostic significance of HIF2alpha/EPAS1 expression in hepatocellular carcinoma. World J Gastroenterol 2007; 13: 3176-3182.

40. Theodoropoulos VE, Lazaris ACh, Sofras F, Gerzelis I, Tsoukala V, Ghikonti I et al. Hypoxia-inducible factor 1 alpha expression correlates with angiogenesis and unfavorable prognosis in bladder cancer. Eur Urol 2004; 46: 200-208.

41. Irie N, Matsuo T, Nagata I. Protocol of radiotherapy for glioblastoma according to the expression of HIF-1. Brain Tumor Pathol 2004; 21: 1-6.

42. Giatromanolaki A, Sivridis E, Kouskoukis C, Gatter KC, Harris AL, Koukourakis Ml et al. Hypoxia-inducible factors 1alpha and 2alpha are related to vascular endothelial growth factor expression and a poorer prognosis in nodular malignant melanomas of the skin. Melanoma Res 2003; 13: 493-501.

43. Giatromanolaki A, Koukourakis MI, Sivridis E, Turley H, Talks K, Pezzella F et al. Relation of hypoxia inducible factor 1 alpha and 2 alpha in operable non-small cell lung cancer to angiogenic/molecular profile of tumours and survival. Br J Cancer 2001; 85: 881-890.

44. Biju MP, Neumann AK, Bensinger SJ, Johnson RS, Turka LA, Haase VH. Vhlh gene deletion induces Hif-1-mediated cell death in thymocytes. Mol Cell Biol 2004; 24 9038-9047.

45. Vaupel $P$, Mayer A. Hypoxia in cancer: significance and impact on clinical outcome Cancer Metastasis Rev 2007; 26: 225-239.

46. Kim SJ, Rabbani ZN, Dewhirst MW, Vujaskovic Z, Vollmer RT, Schreiber EG et al Expression of HIF-1alpha, CA IX, VEGF, and MMP-9 in surgically resected non-small cell lung cancer. Lung Cancer 2005; 49: 325-335.

47. Maxwell PH, Wiesener MS, Chang GW, Clifford SC, Vaux EC, Cockman ME et al. The tumour suppressor protein $\mathrm{VHL}$ targets hypoxia-inducible factors for oxygen-dependent proteolysis [see comments]. Nature 1999; 399: 271-275

48. Iliopoulos O, Levy AP, Jiang C, Kaelin Jr WG, Goldberg MA. Negative regulation of hypoxia-inducible genes by the von Hippel-Lindau protein. Proc Natl Acad Sci USA 1996 93: $10595-10599$.

49. Latif F, Tory K, Gnarra J, Yao M, Duh FM, Orcutt ML et al. Identification of the von HippelLindau disease tumor suppressor gene. Science 1993; 260: 1317-1320.

50. Gnarra JR, Glenn GM, Latif F, Anglard P, Lerman MI, Zbar B et al. Molecular genetic studies of sporadic and familial renal cell carcinoma. Urol Clin North Am 1993; 20 207-216.

51. Sprenger SH, Gijtenbeek JM, Wesseling P, Sciot R, van Calenbergh F, Lammens $M$ et al. Characteristic chromosomal aberrations in sporadic cerebellar hemangioblastomas revealed by comparative genomic hybridization. J Neurooncol 2001; 52: 241-247.

52. Mazure NM, Chen EY, Laderoute KR, Giaccia AJ. Induction of vascular endothelial growth factor by hypoxia is modulated by a phosphatidylinositol 3-kinase/Akt signaling pathway in Ha-ras-transformed cells through a hypoxia inducible factor-1 transcriptional element. Blood 1997; 90: 3322-3331.

53. Zelzer E, Levy $Y$, Kahana C, Shilo BZ, Rubinstein M, Cohen B. Insulin induces transcription of target genes through the hypoxia-inducible factor HIF-1alpha/ARNT. EMBO J 1998; 17: 5085-5094

54. Jiang BH, Jiang G, Zheng JZ, Lu Z, Hunter T, Vogt PK. Phosphatidylinositol 3-kinase signaling controls levels of hypoxia-inducible factor 1. Cell Growth Differ 2001; 12 363-369.

55. Zundel W, Schindler C, Haas-Kogan D, Koong A, Kaper F, Chen E et al. Loss of PTEN facilitates HIF-1-mediated gene expression. Genes Dev 2000; 14: 391-396.

56. Brugarolas JB, Vazquez F, Reddy A, Sellers WR, Kaelin Jr WG. TSC2 regulates VEGF through mTOR-dependent and -independent pathways. Cancer Cell 2003; 4: 147-158.

57. Majumder PK, Febbo PG, Bikoff R, Berger R, Xue Q, McMahon LM et al. mTOR inhibition reverses Akt-dependent prostate intraepithelial neoplasia through regulation of apoptotic and HIF-1-dependent pathways. Nat Med 2004; 10: 594-601.

58. Hudson CC, Liu M, Chiang GG, Otterness DM, Loomis DC, Kaper F et al. Regulation of hypoxia-inducible factor 1alpha expression and function by the mammalian target of rapamycin. Mol Cell Biol 2002; 22: 7004-7014.

59. Hanahan D, Weinberg RA. The hallmarks of cancer. Cell 2000; 100: 57-70.

60. Carmeliet $P$, Jain RK. Angiogenesis in cancer and other diseases. Nature 2000; 407: 249-257.

61. Hickey MM, Simon MC. Regulation of angiogenesis by hypoxia and hypoxia-inducible factors. Curr Top Dev Biol 2006; 76: 217-257.

62. Dvorak HF. Vascular permeability factor/vascular endothelial growth factor: a critical cytokine in tumor angiogenesis and a potential target for diagnosis and therapy. $J$ Clin Oncol 2002; 20: 4368-4380.

63. Ryan HE, Lo J, Johnson RS. HIF-1 alpha is required for solid tumor formation and embryonic vascularization. EMBO J 1998; 17: 3005-3015.

64. Carmeliet P, Dor Y, Herbert JM, Fukumura D, Brusselmans K, Dewerchin M et al. Role of HIF-1alpha in hypoxia-mediated apoptosis, cell proliferation and tumour angiogenesis. Nature 1998; 394: 485-490.

65. Chavez JC, Baranova O, Lin J, Pichiule P. The transcriptional activator hypoxia inducible factor 2 (HIF-2/EPAS-1) regulates the oxygen-dependent expression of erythropoietin in cortical astrocytes. J Neurosci 2006; 26: 9471-9481.

66. Raval RR, Lau KW, Tran MG, Sowter HM, Mandriota SJ, Li JL et al. Contrasting properties of hypoxia-inducible factor 1 (HIF-1) and HIF-2 in von Hippel-Lindauassociated renal cell carcinoma. Mol Cell Biol 2005; 25: 5675-5686.

67. Covello KL, Simon MC, Keith B. Targeted replacement of hypoxia-inducible factor-1alpha by a hypoxia-inducible factor-2alpha knock-in allele promotes tumor growth. Cancer Res 2005; 65: 2277-2286

68. Warburg O. On the origin of cancer cells. Science 1956; 123: 309-314.

69. Semenza GL. HIF-1 mediates the Warburg effect in clear cell renal carcinoma. J Bioenerg Biomembr 2007; 39: 231-234.

70. Zhang H, Gao P, Fukuda R, Kumar G, Krishnamachary B, Zeller KI et al. HIF-1 inhibits mitochondrial biogenesis and cellular respiration in $\mathrm{VHL}$-deficient renal cell carcinoma by repression of C-MYC activity. Cancer Cell 2007; 11: 407-420.

71. Kondo K, KIco JM, Nakamura E, Lechpammer M, kaelin WG. Inhibition of HIF is necessary for tumor suppression by the von Hippel-Lindau protein. Cancer Cell 2002; 1 237-246.

72. Kondo K, Kim WY, Lechpammer M, Kaelin Jr WG. Inhibition of HIF2alpha is sufficient to suppress pVHL-defective tumor growth. PLOS Biol 2003; 1: E83.

73. Arabi A, Wu S, Ridderstråle $\mathrm{K}$, Bierhoff $\mathrm{H}$, Shiue $\mathrm{C}$, Fatyol $\mathrm{K}$ et al. c-Myc associates with ribosomal DNA and activates RNA polymerase I transcription. Nat Cell Biol 2005; 7 303-310.

74. Gordan JD, Bertout JA, Hu CJ, Diehl JA, Simon MC. HIF-2alpha promotes hypoxic cell proliferation by enhancing c-myc transcriptional activity. Cancer Cell 2007; 11: 335-347.

75. Bindra RS, Vasselli JR, Stearman R, Linehan WM, Klausner RD. VHL-mediated hypoxia regulation of cyclin D1 in renal carcinoma cells. Cancer Res 2002; 62: 3014-3019.

76. Imai T, Horiuchi A, Wang C, Oka K, Ohira S, Nikaido T et al. Hypoxia attenuates the expression of E-cadherin via up-regulation of SNAIL in ovarian carcinoma cells. Am J Pathol 2003; 163: 1437-1447.

77. Esteban MA, Tran MG, Harten SK, Hill P, Castellanos MC, Chandra A et al. Regulation of E-cadherin expression by VHL and hypoxia-inducible factor. Cancer Res 2006; 66 3567-3575.

78. Evans AJ, Russell RC, Roche O, Burry TN, Fish JE, Chow VW et al. VHL promotes E2 box-dependent E-cadherin transcription by HIF-mediated regulation of SIP1 and snail. Mol Cell Biol 2007; 27: 157-169.

79. Erler JT, Bennewith KL, Nicolau M, Dornhöfer N, Kong C, Le QT et al. Lysyl oxidase is essential for hypoxia-induced metastasis. Nature 2006; 440: 1222-1226.

80. Arya M, Ahmed H, Silhi N, Williamson M, Patel HR. Clinical importance and therapeutic implications of the pivotal CXCL12-CXCR4 (chemokine ligand-receptor) interaction in cancer cell migration. Tumour Biol 2007; 28: 123-131.

81. Phillips RJ, Mestas J, Gharaee-Kermani M, Burdick MD, Sica A, Belperio JA et al. Epidermal growth factor and hypoxia-induced expression of CXC chemokine receptor 4 on non-small cell lung cancer cells is regulated by the phosphatidylinositol 3-kinase/ PTEN/AKT/mammalian target of rapamycin signaling pathway and activation of hypoxia inducible factor-1alpha. J Biol Chem 2005; 280: 22473-22481. 
82. Zagzag D, Lukyanov Y, Lan L, Ali MA, Esencay M, Mendez O. Hypoxia-inducible factor 1 and VEGF upregulate CXCR4 in glioblastoma: implications for angiogenesis and glioma cell invasion. Lab Invest 2006; 86: 1221-1232.

83. Staller P, Sulitkova J, Lisztwan J, Moch H, Oakeley EJ, Krek W. Chemokine receptor CXCR4 downregulated by von Hippel-Lindau tumour suppressor pVHL. Nature 2003 425: 307-311.

84. Ceradini DJ, Kulkarni AR, Callaghan MJ, Tepper OM, Bastidas N, Kleinman ME et al. Progenitor cell trafficking is regulated by hypoxic gradients through HIF-1 induction of SDF-1. Nat Med 2004; 10: 858-864.

85. Reya T, Morrison SJ, Clarke MF, Weissman IL. Stem cells, cancer, and cancer stem cells Nature 2001; 414: 105-111.

86. Gustafsson MV, Zheng X, Pereira T, Gradin K, Jin S, Lundkvist J et al. Hypoxia requires notch signaling to maintain the undifferentiated cell state. Dev Cell 2005; 9: 617-628.

87. Yun Z, Maecker HL, Johnson RS, Giaccia AJ. Inhibition of PPAR gamma 2 gene expression by the HIF-1-regulated gene DEC1/Stra13: a mechanism for regulation of adipogenesis by hypoxia. Dev Cell 2002; 2 : 331-341

88. Jögi A, Øra I, Nilsson $H$, Poellinger L, Axelson H, Påhlman S. Hypoxia-induced dedifferentiation in neuroblastoma cells. Cancer Lett 2003; 197: 145-150.

89. Helczynska K, Kronblad A, Jögi A, Nilsson E, Beckman S, Landberg G et al. Hypoxia promotes a dedifferentiated phenotype in ductal breast carcinoma in situ. Cancer Res 2003; 63: 1441-1444.

90. Parmar K, Mauch P, Vergilio JA, Sackstein R, Down JD. Distribution of hematopoietic stem cells in the bone marrow according to regional hypoxia. Proc Natl Acad Sci USA 2007; 104: 5431-5436.

91. Lee YM, Jeong CH, Koo SY, Son MJ, Song HS, Bae SK et al. Determination of hypoxic region by hypoxia marker in developing mouse embryos in vivo: a possible signal for vessel development. Dev Dyn 2001; 220: 175-186.

92. Ezashi $\mathrm{T}$, Das $\mathrm{P}$, Roberts RM. Low $\mathrm{O}_{2}$ tensions and the prevention of differentiation of hES cells. Proc Natl Acad Sci USA 2005; 102: 4783-4788.

93. Takahashi K, Yamanaka S. Induction of pluripotent stem cells from mouse embryonic and adult fibroblast cultures by defined factors. Cell 2006; 126: 663-676.
94. Covello KL, Kehler J, Yu H, Gordan JD, Arsham AM, Hu CJ. HIF-2alpha regulates Oct-4: effects of hypoxia on stem cell function, embryonic development, and tumor growth. Genes Dev 2006; 20: 557-570.

95. Acker T, Diez-Juan A, Aragones J, Tjwa M, Brusselmans K, Moons L et al. Genetic evidence for a tumor suppressor role of HIF-2alpha. Cancer Cell 2005; 8: 131-141.

96. Mack FA, Rathmell WK, Arsham AM, Gnarra J, Keith B, Simon MC. Loss of pVHL is sufficient to cause HIF dysregulation in primary cells but does not promote tumor growth. Cancer Cell 2003; 3: 75-88.

97. Koshiji M, Kageyama Y, Pete EA, Horikawa I, Barrett JC, Huang LE. HIF-1alpha induces cell cycle arrest by functionally counteracting Myc. EMBO J 2004; 23: 1949-1956.

98. Bruick RK. Expression of the gene encoding the proapoptotic Nip3 protein is induced by hypoxia. Proc Natl Acad Sci USA 2000; 97: 9082-9087.

99. Sowter HM, Ratcliffe PJ, Watson P, Greenberg AH, Harris AL. HIF-1-dependent regulation of hypoxic induction of the cell death factors BNIP3 and NIX in human tumors. Cancer Res 2001; 61: 6669-6673.

100. Tracy K, Dibling BC, Spike BT, Knabb JR, Schumacker P, Macleod KF. BNIP3 is an $\mathrm{RB} / \mathrm{E} 2 \mathrm{~F}$ target gene required for hypoxia-induced autophagy. Mol Cell Biol 2007; 27: 6229-6242.

101. Biju MP, Akai Y, Shrimanker N, Haase VH. Protection of HIF-1-deficient primary renal tubular epithelial cells from hypoxia-induced cell death is glucose dependent. $A m \mathrm{~J}$ Physiol Renal Physiol 2005; 289: F1217-F1226.

102. Moeller BJ, Cao Y, Li CY, Dewhirst MW. Radiation activates HIF-1 to regulate vascular radiosensitivity in tumors: role of reoxygenation, free radicals, and stress granules. Cancer Cell 2004; 5: 429-441.

103. Moeller BJ, Dreher MR, Rabbani ZN, Schroeder T, Cao Y, Li CY et al. Pleiotropic effects of HIF-1 blockade on tumor radiosensitivity. Cancer Cell 2005; 8: 99-110.

104. Magnon C, Opolon P, Ricard M, Connault E, Ardouin P, Galaup A et al. Radiation and inhibition of angiogenesis by canstatin synergize to induce HIF-1alpha-mediated tumor apoptotic switch. J Clin Invest 2007; 117: 1844-1855. 